\title{
Nanostructured Materials in Optical Fiber Sensing
}

\author{
M. Hernaez ${ }^{*}$, C. R. Zamarreño, J. Goicoechea, I. R. Matias and F. J. Arregui
}

Electrical and Electronic Engineering Department, Universidad Pública de Navarra: Edif. Los Tejos, Campus Arrosadia, 31006 Pamplona, Spain

\begin{abstract}
This work comprehends a review of nanostructured materials employed in the fabrication of optical fiber sensors in the last years. The continuous advances in nanofabrication techniques have enabled to manipulate the matter precisely producing well defined nanostructurated coatings or repetitive patterns at nanoscale level. The interactions of light with these nano-organized materials or patterns at the nanoscale level enable to observe interesting phenomena, such as interferometry, fluorescence, absorbance, resonances and many others which can be exploited in the fabrication of sensing devices. A particular case consists of optical fiber sensors, where the light travelling through an optical fiber interacts with the sensitive layer. The properties of the sensitive layer, such as the organization, physical properties, chemical bounds etc. will determine the sensing characteristics of the final device. The utilization of some of the most common nanostructured materials, such as polymers, nanoparticles, metals, metal oxides or biological coatings are reviewed here.
\end{abstract}

Keywords: Optical fiber sensors, thin-films, nanostructured coatings, refractometers, biosensors, chemical sensors, metals, metal oxides, polymeric coatings.

\section{INTRODUCTION}

Optical fiber sensors have been established as an emerging technology in many different fields such as biomedicine, environmental control, food quality test or navigation systems [1]. These sensors rely on different physical or chemical principles and can measure multiple magnitudes, for example pressure, temperature or chemical compounds concentrations [2-4]. The very well-known advantages of optical fiber sensors comprise, among many others, the immunity to electromagnetic interferences, easy multiplexation, low weight and transmission losses, small size or real time monitoring $[5,6]$.

Much research has been done in the field of thin-film coated optical waveguides within the last decades $[7,8]$. Nanostructured thin-films when used in conjunction with optical fibers can dramatically improve the performance and functionality of optical fiber sensors [9-12]. However, the fabrication of these micro and nano-coatings is not trivial and requires in most cases a multidisciplinary knowledge [13].

Different thin-film coated optical waveguide configurations have been studied in order to exploit the advantages of the optical fiber configuration in the fabrication of sensing devices, and many of them have been described in different sensing applications and patents [14].

In the next sections, it will be described the utilization of different optical fiber configurations combined with diverse nanostructured materials for the fabrication of optical fiber sensors based on different sensing principles such as

*Address correspondence to this author at the Electrical and Electronic Engineering Department, Universidad Pública de Navarra: Edif. Los Tejos, Campus Arrosadia, 31006 Pamplona, Spain; Tel: +34948166044;

Fax:+34948169720; Email: miguel.hernaez@unavarra.es interferometry, fluorescence, absorbance or electromagnetic resonances.

\section{INTERFEROMETRIC NANO-CAVITIES}

One of the simplest structures that can be fabricated using nanostructured coatings onto optical fibers is an interferometer. It consists of a nanocoating deposited onto the perpendicularly cleaved end of an optical fiber. This coating forms an interferometric cavity schematically represented in (Fig. 1) [15].

\section{Fiber tip}

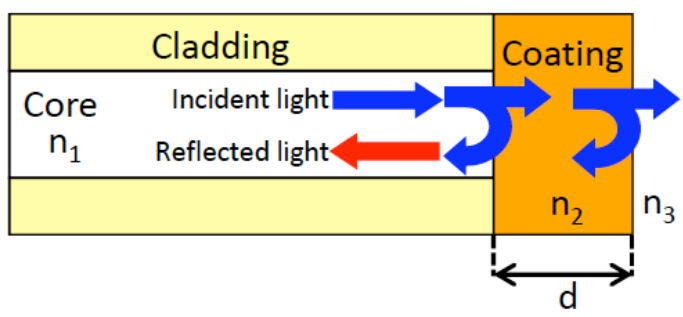

Fig. (1). Schematic representation of an interferometric cavity at the end of an optical fiber.

In this interferometric cavity, two optical mirrors are formed due to the different refractive indices of the optical fiber core (n1), the deposited coating (n2) and the surrounding medium (n3).

The reflectivity depends on the thickness of the coating and the refractive index of the three materials involved (optical fiber core, coating and external medium). Assuming that the optical fiber refractive index is fixed, the reflected power will change if there are changes in the refractive index of the external medium or if the coating suffers any variation. Therefore, in order to detect changes in any magnitude, it is 
just necessary to use a material sensitive to this magnitude to create the coating. This way, the variation in this parameter will produce a variation in the reflected optical power that can be measured with a typical reflection experimental setup.

Light launched from a light source pass through an optical coupler and reaches the interferometer. Part of the optical power is transmitted to the external medium, and the rest is reflected. This reflected power can be measured in the detector after passing again through the coupler. As the thickness of the cavity is shorter than the coherence length of a LED source, it is possible to use this kind of sources, avoiding the use of lasers [16-20]. This fact and the simplicity of this architecture have allowed the development of many kinds of optical fiber sensors based on it.

Different humidity sensors based on interferometric cavities have been developed in the last years. As it has been stated above, a change in the effective refractive index of the deposited coating will produce a variation in the reflected power. This way, if this coating is made of a material which thickness or refractive index is sensitive to humidity changes, the reflected power will represent these variations in the relative humidity of the surrounding medium. For example, in [21], an optical fiber humidity sensor based on $\mathrm{SiO}_{2}$ nanoparticles is presented. It shows a good sensitivity and really fast rise and fall times, improving previous humidity sensors that used polymeric coatings [22].

The utilization of films that change their thickness when the $\mathrm{pH}$ of the external medium varies (swelling/deswelling effect), such as hydrogels or polymers [23], has enabled the fabrication of repetitive and robust $\mathrm{pH}$ sensors. In [24] the well known poly(allylamine hydrochloride) / poly(acrylic acid) (PAH/PAA) structure [25-28] is deposited onto an optical fiber tip to create a $\mathrm{pH}$-sensitive nanocavity.

Interferometric cavities have been used to detect different volatile organic compounds (VOCs). For example, Consales et al. developed $\mathrm{NO}_{2}$ detectors based on this architecture [29-31]. Moreover, ethanol and other VOCs detectors based on vapocromic compounds nanocavities have been fabricated [32-34].

In the last years, some biosensors based on optical fiber interferometers have been developed. For example, in $[35,36]$ a hollow core fiber fragment is used to create a gap between a SMF and the sensing film made of chitosan and PSS. This way, a bovine serum albumine sensor has been fabricated.

\section{FLUORESCENT SENSORS}

An important group of optical fiber sensors consist of those based on fluorescence or phosphorescence measurements, referred as fluorescence henceforward. Fluorescencebased optical fiber sensors have been used traditionally in applications such as analytical chemistry, biochemistry, photochemistry, cellular biology, medical diagnosis or biotechnology for the detection of different compounds with high sensitivity and specificity [37-41]. The fluorescent or phosphorescent dye, used as transducer can be adhered to the optical fiber and is usually entrapped in a matrix with high permeability to the measurand [42-44]. Thus, the sensitivity of the optical sensor depends on both the fluorescence inten- sity of the dye and the matrix characteristics, such as its density, viscosity, hydrophobicity, transparency etc. [45].

Concerning the fluorescence intensity $\left(\mathrm{I}_{\mathrm{f}}\right)$, it is in general proportional to the excitation intensity $\left(\mathrm{I}_{\mathrm{e}}\right)$ and the dye concentration ([D]), which also depends on the quenching effects. It is also important to take into account the fluorescence efficiency $(\eta)$ of the dye, in other words, the ratio between the photons absorbed by the material and the photons emitted by fluorescence or phosphorescence mechanisms. This relation is expressed by Parker's law in 1 .

$\mathrm{I}_{\mathrm{f}}=2.3 \cdot \mathrm{K} \cdot 1 \varepsilon \cdot \mathrm{I}_{\mathrm{e}} \cdot \eta \cdot[\mathrm{D}]$

where 1 is the path length of the light within the detection layer, $\varepsilon$ is the molar absorption coefficient and $\mathrm{K}$ is a fitting factor associated to the geometry of the measurement instrument. However, most of the detection systems do not quantify directly the analyte concentration from the fluorescence intensity but using and indirect approach that compares the fluorescence intensity in absence of analyte $\left(\mathrm{I}_{\mathrm{o}}\right)$ and the fluorescence intensity in the presence of the analyte $\left(\mathrm{I}_{\mathrm{q}}\right)$ which is given by the Stern-Volmer equation in 2 [46].

$\mathrm{I}_{\mathrm{o}} / \mathrm{I}_{\mathrm{Q}}=1+\mathrm{K}_{\mathrm{SV}}[\mathrm{Q}]$

where [Q] is the quencher concentration and $\mathrm{K}_{\mathrm{sv}}$ is the SternVolmer constant, given by the expression $\mathrm{K}_{\mathrm{sv}}=\tau_{\mathrm{o}} \mathrm{k}_{\mathrm{q}}$, where $\mathrm{k}_{\mathrm{q}}$ is the bimolecular deactivation speed constant and $\tau_{\mathrm{o}}$ is the excitation state time.

As it was advanced before, fluorescence emission can be expressed as a function of the quencher target molecule concentration but it is also necessary to take into account other effects that depend on the fluorescent material itself such as the photodegradation or photobleaching that occurs when the indicator is exposed to the excitation source for a long time [47], the selfquenching or self-absorption at high concentrations of fluorophore and the leaking or diffusion loses of the fluorescent indicator molecules through the supporting matrix. In general, the design of an optimum fluorescent sensor requires the selection of dyes with long unquenched state lifetime and matrices with high permeability to the measurand, good mechanical and chemical stability, and none or low interference with the measurements $[48,49]$.

Fluorescent molecules have been traditionally used in the fabrication of optical fiber sensors [45]. These molecules can be easily entrapped into a supporting matrix and adhered to the optical fiber using different fabrication techniques and optical fiber configurations as it is summarised in (Table 1). For instance, the fluorescent dye 1-hydroxy-3,6,8-pyrene trisulfonic acid trisodium salt (also known as pyranine or HPTS) has been used in pH sensing applications [50] as well as $\mathrm{CO}_{2}$ detection in gaseous [51], aqueous [52] or blood [53] media. In the same manner, ruthenium-based coatings have been applied in the fabrication of optical fiber sensors for $\mathrm{pH}$ $[54,55]$ and $\mathrm{O}_{2}[56,57]$ detection, fluorescein-based compounds have been also applied to obtain optical fiber sensing probes for $\mathrm{pH}$ [58-60] or cocaine [61] and eosin red fluorescent dye has been used for $\mathrm{pH}$ [62] and ammonia [63] detection by means of different optical fiber configurations. Fluorescent polymers have been also used for the detection of explosives [64], $\mathrm{Cu}^{2+}$ [65] or $\mathrm{Na}^{+}$[66] ions employing thinfilms fabricated onto fiber end tips, decladded MMFs or MOFs respectively. 
Table 1. Summary of Optical Fiber Sensors Based on Fluorescent Dyes

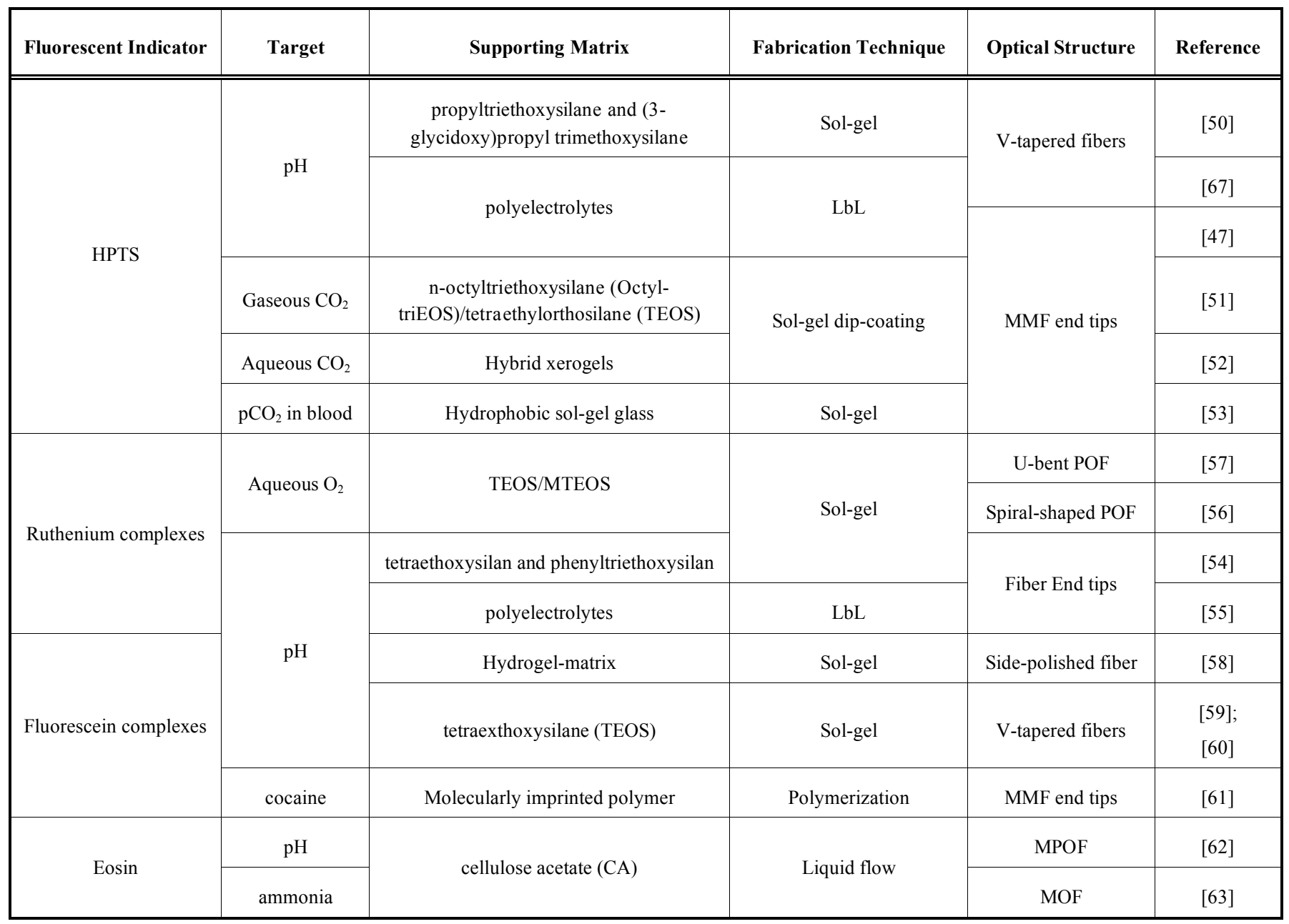

Other materials, such as functionalized carbon dots and vapochromic compounds can also exhibit fluorescence when excited at certain wavelengths. The LbL technique has been used successfully to immobilize both carbon dots and vapochromic compounds onto optical fiber end tips for the detection of $\mathrm{Hg}^{2+}$ ions $[68,69]$ and VOCs [32] respectively. Similarly glucose/galactose binding proteins functionalized with a fluorescent dye have been adhered to an optical fiber end tip within a hydrogel matrix and used for continuous glucose monitoring in animals [70]. Here, the conformational change of the protein in presence of glucose inhibits the fluorescence as it is shown in (Fig. 2).

In this context, luminescent semiconductor nanocrystals, or quantum dots (QDs), are particularly attractive. The unique optical properties of QDs, such as the particle-size dependent luminescence, high efficiency, narrow fluorescence emission band, broad absorption spectrum and high photostability when compared to those of traditional molecular fluorophores, can provide new solutions to many of the problems associated with traditional luminescence sensors and are the promise for a completely new set of applications using different optical fiber configuration [71]. As an example, CdTe quantum dots of various sizes have been embedded in polymeric films using the Layer-by-Layer technique in order to obtain temperature sensors by means of different optical fiber configuration schemes. In [72], the structures have been fabricated onto MMF tapered ends while in [73] and [74] the structures have been fabricated in the inner part of HCFs and in the holes of MOFs respectively (see Fig. 3), which protects the QD nanofilm from the environment while it is still sensitive to temperature changes reducing considerably the effects of photobleaching. Moreover, the utilization of quantum dots of various sizes enabled the utilization of several reference signals [73]. Optical fiber sensing probes for $\mathrm{Cu}^{2+}$ detection were also fabricated in [75] by immobilizing $\mathrm{CdSe} / \mathrm{ZnS}$ quantum dots onto optical fiber tapered end tips using the sol-gel dip-coating technique.

\section{ABSORBANCE-BASED SENSORS}

The transmission of the light through an analyte (T) follows Lambert-Beer's law (ec. 3)

$$
\mathrm{T}=\mathrm{I} / \mathrm{Io}=10^{-\alpha 1}=10^{\varepsilon[\mathrm{C}] 1}
$$

where $I_{o}$ and $I_{f}$ represent the light intensity before and after passing through the sensitive region respectively, 1 is the path length of the light within the absorbing material and $\alpha$ is the absorption coefficient of the indicator, which can be expressed by the product between the molar absorption coefficient $(\varepsilon)$ and the concentration $[C]$ of the target. The 


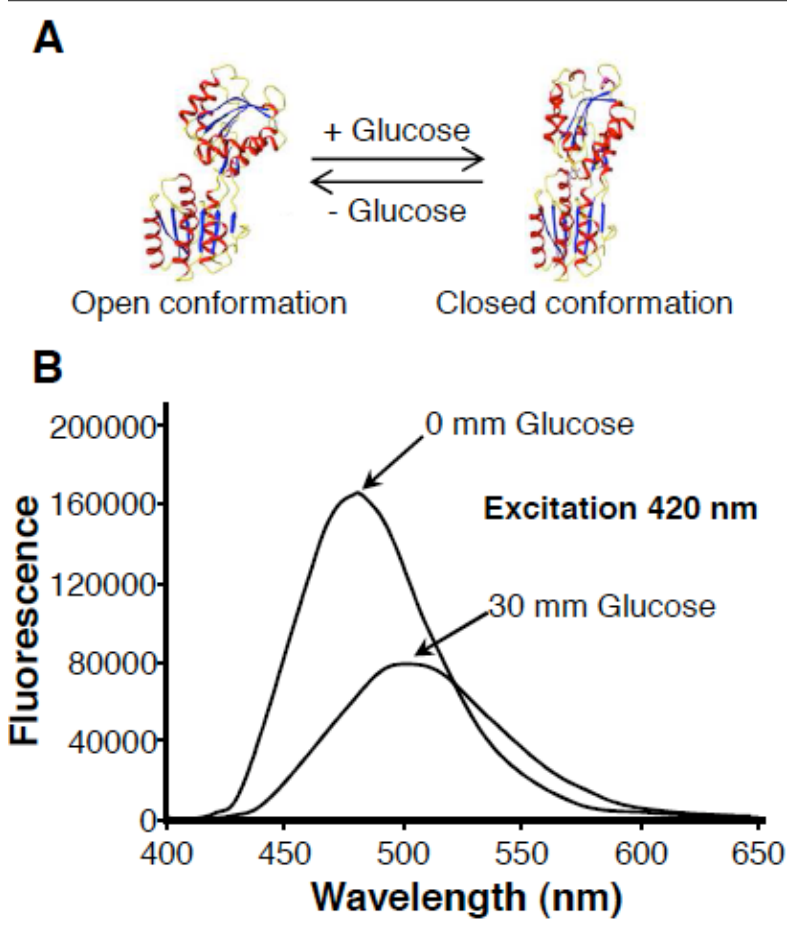

Fig. (2). (A) Ribbon structures depicting the glucose-mediated conformational change of glucose/galactose binding protein (GGBP). Left: Open unliganded conformation of GGBP usin Protein Data Bank structure file 2FW0. Right: the closed or glucose-bound structure of GGBP using Protein Data Bank structure file 2FVY. (B) Fluorescence response of acrylodan-labeled GGBP to glucose. The shaded regions show wavelength bands monitored by the optical system. Extracted from [70] with permission from Elsevier.

logarithmic relation of ec. 3 can be also expressed in terms of absorbance as a linear function of the absorbing material concentration (eq. 4).

$$
\mathrm{A}=-\log _{10} \mathrm{I} / \mathrm{Io}=\alpha \mathrm{l}=\varepsilon[\mathrm{C}] 1
$$

Absorbance-based optical fiber sensors are often used in optical fiber sensing owing to the readout simplicity associated to these devices. The utilization of these sensors relies on the characteristic light absorption of every material and its spectral signature. However, this requires complex discrimination algorithms and sometimes tedious learning process in order to obtain optimum results [76-78]. An alternative approach comprises the utilization of an active indicator as the transducer. The generic idea is that the active indicator changes its optical properties (absorbance) depending on the presence or concentration of the sole target to be measured, which enables to determine the target concentration. In order to maximize the interactions of the light with the indicator, the latter can be adhered, directly or immersed in a supporting matrix, to the fiber surface. Therefore, the matrix properties together with the optical fiber geometry will determine the penetration depth of the evanescent field within the sensitive structure and it will be crucial in the overall response of this kind of sensors [79]. The next paragraphs will focus the attention in the utilization of thin absorbing films adhered to different optical fiber schemes for the fabrication of optical fiber sensors as it is summarized in (Table 2).
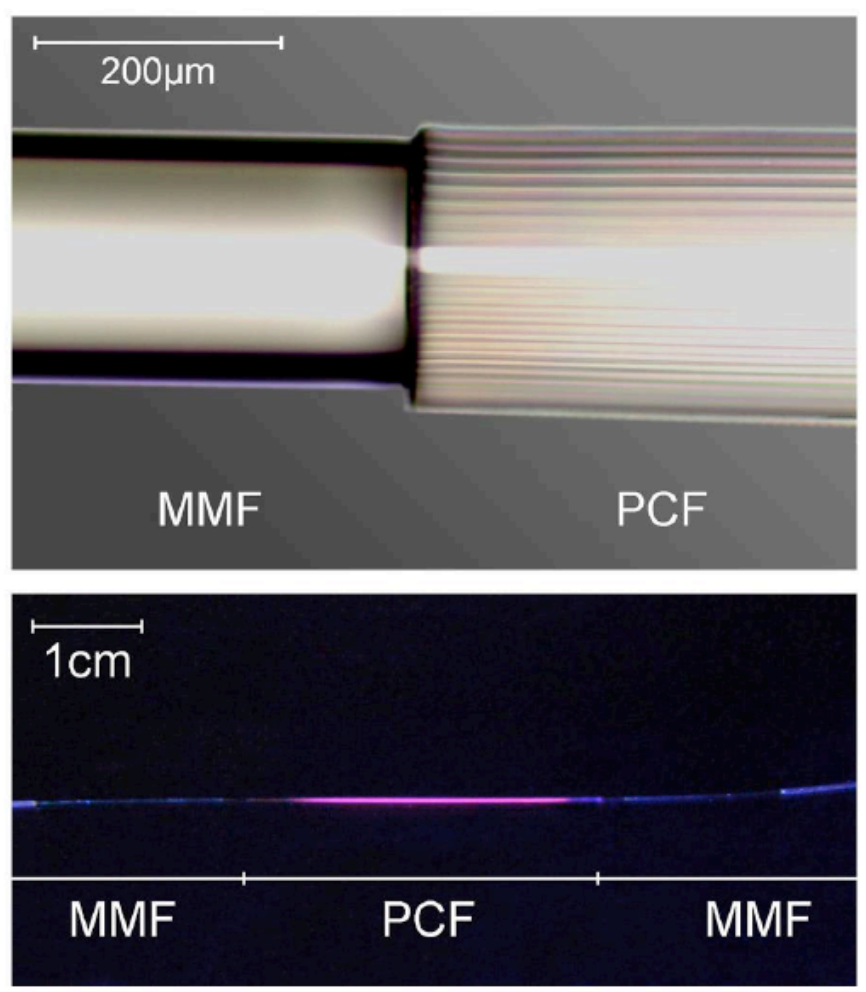

Fig. (3). Top: Microscope image of the MOF-MMF splices. Bottom: Picture of the optical fiber arrangement under UV illumination. In the middle region the red quantum dots' fluorescence from the MOF inner holes can be seen. Extracted from [74] under Creative Commons License.

In general, the optical fiber schemes employed are intended to grant the major access to the light travelling through the optical fiber core in order to maximize the interactions of the light with the active thin-film. Bent fibers can be an interesting choice to increase the evanescent field and hence the interactions with the surrounding active media as it is described by several authors for the fabrication of humidity [80,81], $\mathrm{pH}$ [82], ammonia [83], $\mathrm{H}_{2} \mathrm{O}_{2}$ [84] and $\mathrm{Hg}^{2+}$ [85] sensors.

An alternative approach and one of the preferred embodiments due to its simplicity consists of the removal of the optical fiber cladding and the fabrication of the thin-film directly onto the optical fiber core. This, configuration is usually referred as cladding removed (CR) followed by the optical fiber type such as multi-mode fiber (MMF) or plastic optical fiber (POF) and have been largely exploited in literature for the development of optical fiber sensors for ammonia [86,87], humidity [88,89], toluene [90], $\mathrm{H}_{2} \mathrm{~S}[91,92]$, aerosol [93] or $\mathrm{pH}$ [94-104] detection.

Other options aimed to maximize light interactions with the sensitive film comprise the modification of the regular optical fiber structure or the utilization of special optical fibers. As regard as the modification of the optical fiber structure it can be mentioned the fabrication of optical fiber sensors by means of hetero-core optical fibers (HCOF) [105-107], tapers [22, 108, 109] or side-polished fibers 
Table 2. Summary of Optical Fiber Sensors Based on Absorbance Measurements

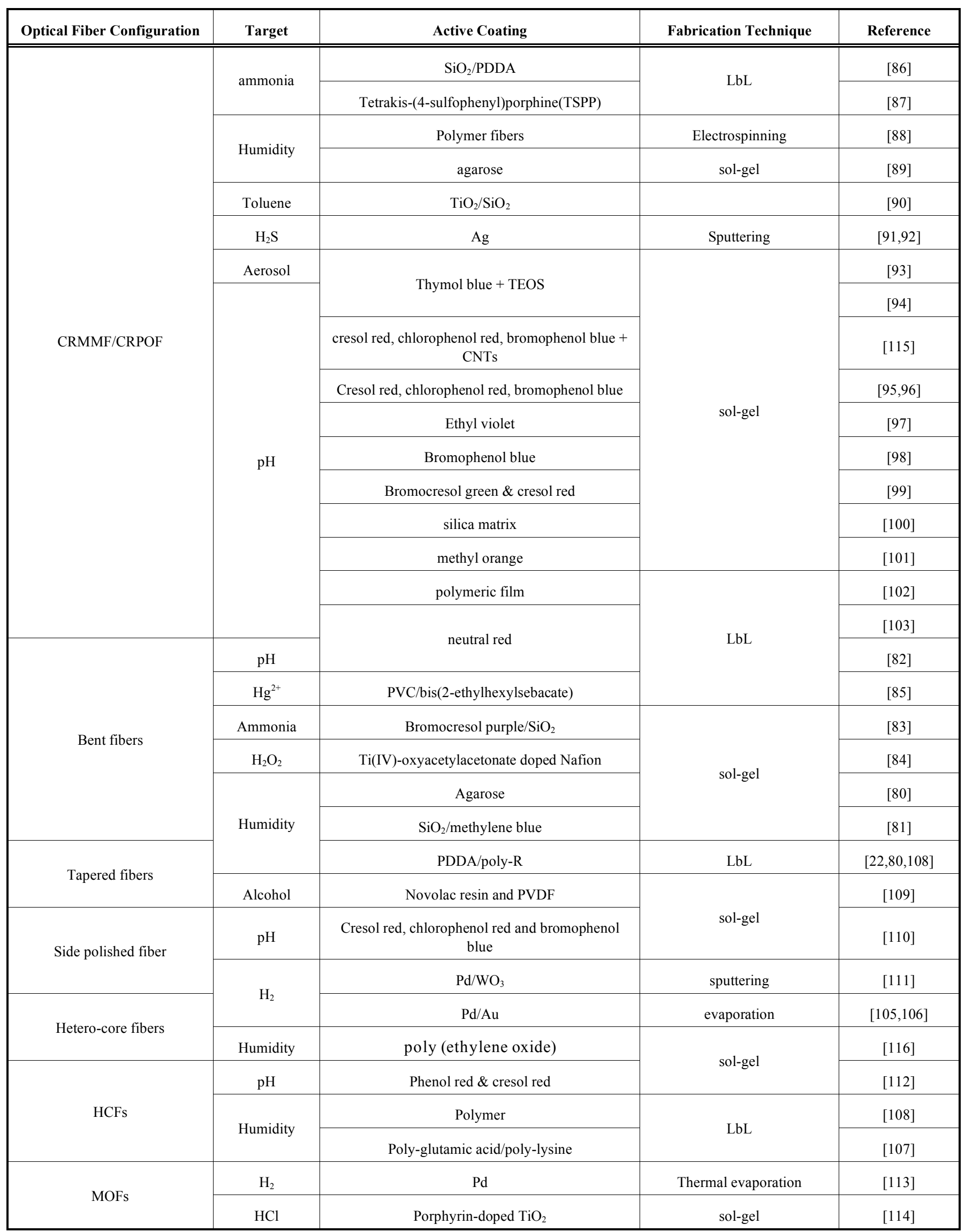


$[110,111]$ while the use of special optical fibers for the fabrication of sensors is mainly referred to hollow-core fibers (HCFs) $[112,108]$ and microstructured optical fibers (MOFs) [113, 114].

\section{RESONANCE-BASED SENSORS}

When an optical waveguide is coated by a thin-film (see Fig. 4), the propagation of light is affected. Depending on the properties of the different materials involved in the system (the waveguide, the coating and the external medium), three different cases of electromagnetic resonances can be distinguished [117].

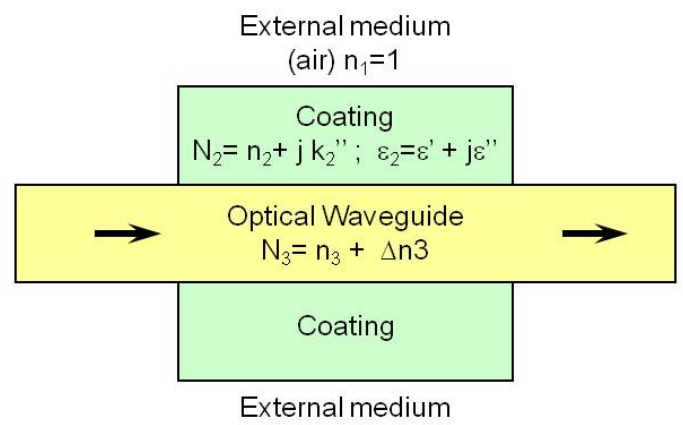

(air)

Fig. (4). Schematic representation of the optical system used to obtain electromagnetic resonances.

The first case occurs when the real part of the thin-film permittivity is negative and higher in magnitude than both its own imaginary part and the permittivity of the material surrounding the thin film. In this case, a resonance called Surface Plasmon Resonance (SPR) is produced.

The second case occurs when the real part of the thinfilm permittivity is positive and higher in magnitude than both its own imaginary part and the permittivity of the material surrounding the thin film. In these conditions a second type of resonances called Lossy Mode Resonance (LMR) is produced.

Finally, the third case occurs when the real part of the thin-film permittivity is close to zero, while the magnitude of its imaginary part is large. This case, known as long-range surface exciton polariton (LRSEP), has not been applied to the fabrication of optical fiber sensors and will not be included in this review.

The system showed in (Fig. 4) can be easily adapted to optical fiber. The uncladded core of an optical fiber is used as a waveguide and the appropriate coating is deposited onto it. This device is connected in both extremes to an optical source and a detector to obtain the complete interrogation setup [118].

When an electromagnetic resonance (EMR) (SPR or LMR) is produced, the generated absorption peak shifts to different wavelengths when the refractive index of the external medium changes.

SPR have become an optical fiber sensor standard in the last years, with a lot of research done in this field. For example, different optical fiber refractometers based on SPR have been developed by using MMF, SMF or tapered fiberschemes [118-125].

If the SPR supporting thin film (usually a metal) is coated with any material which refractive index is sensitive to some magnitude, a variation in this magnitude will produce a shift in the SPR absorption peak. This architecture has been applied for the fabrication of different optical fiber sensors. For example, in [126] a pH sensor was fabricated by adding a $\mathrm{pH}$-sensitive hydrogel to a SPR supporting coating. In addition, different sensors based on SPR have been developed for the detection of volatile organic compounds (VOC), such as alkanes [127, 128] or ammonia [129].

However, the fabrication of biological sensors is the field where SPR-based optical fiber sensors have acquired the main interest $[130,131]$. These sensors include biologically active structures that detect the target, such as bacterial cells, enzymes, antibodies and other proteins and allow the detection of proteins [132], viruses [133, 134], pesticides [135], living cells [136], etc.

As it has been mentioned, the apparition of SPR devices has supposed an important breakthrough in the field of optical fiber sensors. But this phenomenon have some limitations, such as the necessity of using polarized light or the fact that it is only generated by some specific metals.

Recently, the first optical fiber sensors based on LMR have appeared using LMR supporting coatings from different nature. Thus, optical fiber refractometers including different metal oxides have been fabricated [137-139]. These sensors present sensitivities in the range of similar SPRbased sensors, but the experimental setup and the fabrication procedure are simpler.

In addition, sensors based on these refractometers have been developed by just adding a sensitive coating to the previous device. For example, polymeric coatings were deposited onto the LMR supporting devices in order to obtain humidity and $\mathrm{pH}$ sensors $[27,140,141]$.

However, metal oxides are not the only materials that can generate LMR. In [142] a refractometer based on $\mathrm{TiO}_{2}$ nanoparticles is presented and in [143], a polymeric coating is simultaneously used as LMR supporting coating and sensitive coating in order to obtain a $\mathrm{pH}$ sensor with a really fast and sensitive response and low hysteresis (Fig. 5).

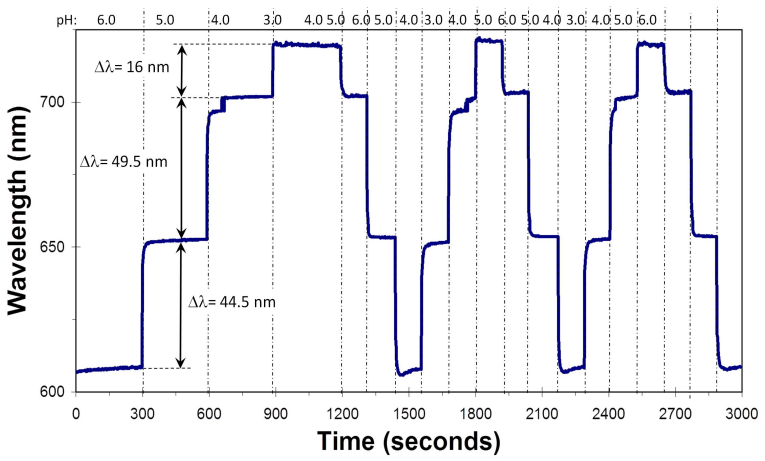

Fig. (5). Dynamical response of a $\mathrm{pH}$ sensor based on LMR generated onto a polymeric coating. Extracted from [143] with permission from Elsevier. 
Table 3. Summary of Optical Fiber Sensors Based on Electromagnetic Resonances

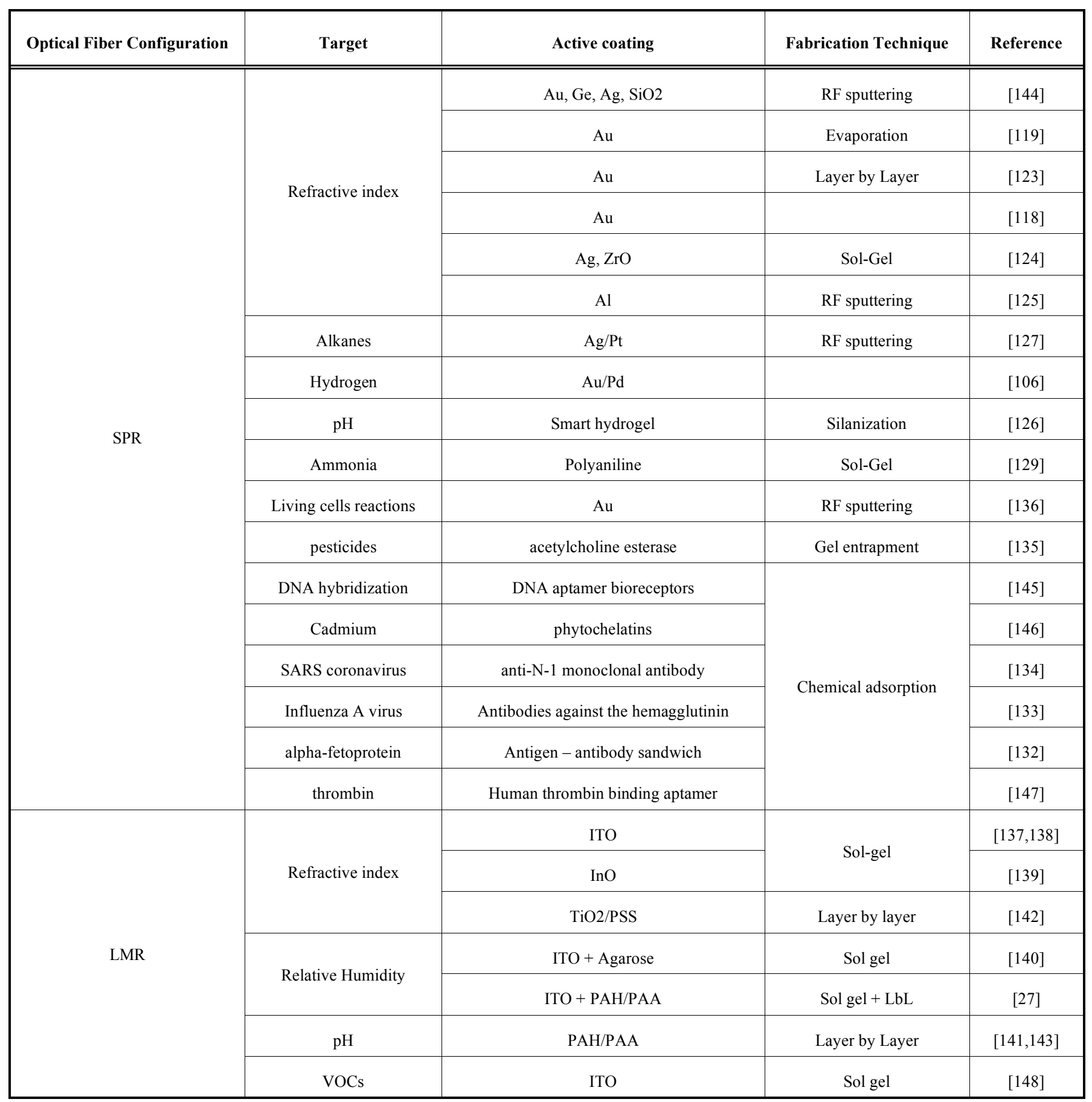

In (Table 3) a summary with different examples of optical fiber sensors based on SPR and LMR is shown.

\section{CONCLUSIONS}

This paper has reviewed four categories of nanostructured optical fiber sensors based on fluorescence, absorbance, interferometric nano-cavities and electromagnetic resonances. All these sensors rely on the interactions of light with the nanostructured thin-films. The sensing mechanism behind each category and current state of the art has been presented.

\section{FUTURE DEVELOPMENTS}

In the last few years, different studies have shown the excellent potential of carbon derivates as sensitive materials for the detection of ambient pollutants. The particular structure of these carbon-based materials and their unique properties such as their tensile strength, high surface area, low density as well as their exceptional electrical and thermal properties make them very attractive to produce small and portable sensors usable on many different substrates [149] such as optical fibers $[30,29,150]$. A step forward could be the functionalisation of these carbon-based structures that can 
include fullerenes, graphene films, carbon nanotubes, nanoporous carbon films and diamond like carbon films among others in order to increase their sensitivity and minimize the undesired effects like cross-sensitivity [151].

Additionally, the utilization of metal-organic framework materials could also expand the challenges in the design and synthesis of structures with exceptionally high surface areas. (up to $3,000 \mathrm{~m}^{2} \mathrm{~g}^{-1}$ ) [152] while the investigation of the sensing properties of these porous materials combined with optical fibers is still an unexplored field.

\section{CONFLICT OF INTEREST}

The authors confirm that this article content has no conflicts of interest.

\section{ACKNOWLEDGEMENTS}

This work was supported by the Spanish Ministry of Education and Science-FEDER TEC2010-17805 and Government of Navarra research grants.

\section{REFERENCES}

[1] Culshaw B. Optical fiber sensor technologies: opportunities and perhaps - pitfalls. J Lightwave Technol 2004; 22(1): 39-50.

[2] Culshaw B, Kersey A. Fiber-optic sensing: A historical perspective. J Lightwave Technol 2008; 26(9): 1064-78.

[3] Cusano A, López-Higuera JM, Matias IR, Culshaw B. Editorial optical fiber sensor technology and applications. IEEE Sens J 2008; 8(7): 1052-4.

[4] Elosua C, Bariain C, Matias IR. Optical fiber sensing applications: detection and identification of gases and volatile organic compounds. In: Yasin M, Sulaiman WH, Hamzah A, Eds. Fiber Optic Sensors. Intech 2012; pp. 27-52.

[5] Strobel O, Seibl D, Lubkoll J, Rejeb R. ICTON 2009. 11th International Conference on Transparent Optical Networks 2009.

[6] Jaroszewicz LR, Culshaw B, Mignani AG. Proceedings SPIE 5952, Optical Fibers: Applications, 595201; 2005.

[7] James SW, Tatam RP. Fibre optic sensors with nano-structured coatings. J Opt A Pure Appl Opt 2006; 8(7): 430-44.

[8] Arregui FJ, Matias IR, Corres JM, et al. Procedia Eng 2010; 5(0):1087-90.

[9] Sun K, Wu N, Guthy C, Wang X. Nanomaterial fiber optic sensors in healthcare and industry applications. In: Lu K, Manjooran N, Radovic M, Eds. Advances in nanomaterials and nanostructures. New Jersey: John Wiley 2011; vol 229: pp. 163-70.

[10] Arregui FJ, Matias IR, Goicoechea J, Del Villar I. Optical fiber sensors based on nanostructured coatings. In: Arregui FJ, Ed. Sensors based on nanostructured materials. New York: Springer 2009; pp. 275-301.

[11] Consales M, Ricciardi A, Crescitelli A, Esposito E, Cutolo AC, Cusano A. Lab-on-Fiber Technology: Toward Multifunctional Optical Nanoprobes. ACS Nano 2012; 6 (4): 3163-70.

[12] Esposito E, Granata C, Crescitelli A, et al. 10th IEEE SENSORS Conference 2011, October 2011; 2011.

[13] Zamarreño CR, Matias IR, Arregui FJ. Nanofabrication techniques applied to the development of novel optical fiber sensors based on nanostructured coatings. IEEE Sens J 2012; 12(8): 2699-710.

[14] Zamarreño CR, Corres JM, Goicoechea J, Del Villar I, Arregui FJ, Matias IR. Fiber-Optic nanosensors. In: Cusano A, Arregui FJ, Giordano M, Cutolo A, Eds. Optochemical nanosensors: Tylor \& Francis 2012; pp. 163-200.

[15] Arregui FJ. Sensors based on nanostructured materials. S New York: Springer 2009.

[16] Arregui FJ, Matias IR, Liu Y, Lenahan KM, Claus RO. Optical fiber nanometer-scale Fabry-Perot interferometer formed by the ionic self-assembly monolayer process. Opt Lett 1999; 24(9): 5968 .
[17] Arregui FJ, Liu Y, Matias IR, Claus RO. Optical fiber humidity sensor using a nano Fabry-Perot cavity formed by the ionic selfassembly method. Sens Actuator B-Chem 1999; 59(1): 54-9.

[18] Arregui FJ, Latasa I, Matias IR, Claus RO. Proceedings of IEEE Sensors 2003; 2004

[19] Del Villar I, Achaerandio M, Matías IR, Arregui FJ. Deposition of overlays by electrostatic self-assembly in long-period fiber gratings. Opt Lett 2005; 30(7): 720-2.

[20] Del Villar I, Matias IR, Arregui FJ, Claus RO. ESA-based in-fiber nanocavity for hydrogen-peroxide detection. IEEE Trans Nanotechnol 2005; 4(2): 187-93.

[21] Corres JM, Matias IR, Hernaez M, Bravo J, Arregui FJ. Optical fiber humidity sensors using nanostructured coatings of $\mathrm{SiO}_{2}$ nanoparticles. IEEE Sens J 2008; 8(3): 281-4.

[22] Corres JM, Arregui FJ, Matías IR. Sensitivity optimization of tapered optical fiber humidity sensors by means of tuning the thickness of nanostructured sensitive coatings. Sens Actuators B-Chem 2007; 122(2): 442-9.

[23] Hiller J, Rubner MF. Reversible molecular memory and $\mathrm{pH}-$ switchable swelling transitions in polyelectrolyte multilayers. Macromolecules 2003; 36(11): 4078-83.

[24] Zamarreño CR, Goicoechea J, Matias IR, Arregui FJ. MRS Fall Meeting 2008: Polymer-Based Smart Materials - Processes, Properties and Application 2009.

[25] Corres JM, Del Villar I, Matias IR, Arregui FJ. Fiber-optic pHsensors in long-period fiber gratings using electrostatic selfassembly. Opt Lett 2007; 32(1): 29-31.

[26] Goicoechea J, Zamarreño CR, Matias IR, Arregui FJ. Utilization of white light interferometry in $\mathrm{pH}$ sensing applications by mean of the fabrication of nanostructured cavities. Sens Actuators B-Chem 2009; 138(2): 613-8

[27] Zamarreño CR, Hernaez M, Del Villar I, Matias IR, Arregui FJ. Tunable humidity sensor based on ITO-coated optical fiber. Sens Actuators B-Chem 2010; 146(1): 414-7.

[28] Gu B, Yin MJ, Zhang AP, Qian JW, He S. Low-cost highperformance fiber-optic $\mathrm{pH}$ sensor based on thin-core fiber modal interferometer. Opt Express 2009; 17(25): 22296-302.

[29] Crescitelli A, Consales M, Cutolo A, et al. IEEE Sens 2008; 2008 2009.

[30] Consales M, Crescitelli A, Penza M, et al. SWCNT nanocomposite optical sensors for VOC and gas trace detection. Sens Actuators B-Chem 2009; 138(1): 351-61.

[31] Consales M, Crescitelli A, Penza M, et al. Opt Sen 2008; 2008; 2008.

[32] Elosua C, Bariain C, Matias IR, et al. Indicator immobilization on Fabry-Perot nanocavities towards development of fiber optic sensors. Sens Actuators B-Chem 2008; 130(1): 158-63.

[33] Elosua C, Matias IR, Bariain C, Arregui FJ. Development of an infiber nanocavity towards detection of volatile organic gases. Sensors 2006; 6(6): 578-92.

[34] Elosua C, Perez-Herrera RA, Lopez-Amo M, Bariain C, Luquin A, Laguna M. Proceedings of SPIE 7503: 20th International Conference on Optical Fibre Sensors 2009; 2009 .

[35] Chen LH, Li T, Chan CC, et al. Chitosan based fiber-optic FabryPerot humidity sensor. Sens Actuators B-Chem 2012; 169: 167-72.

[36] Chen LH, Ang XM, Chan CC, et al. Layer-by-layer (chitosan/polystyrene sulfonate) membrane-based fabry-perot interferometric fiber optic biosensor. IEEE J Sel Top Quantum Electron 2012; 18(4): 1457-64.

[37] Tormo L, Bustamante N, Colmenarejo G, Orellana G. Can luminescent $\mathrm{Ru}(\mathrm{II})$ Polypyridyl dyes measure $\mathrm{pH}$ directly? Anal Chem 2010; 82(12): 5195-204

[38] Borisov SM, Wolfbeis OS. Optical biosensors. Chem Rev 2008; 108(2): 423-61.

[39] Wolfbeis OS, Kovacs B, Goswami K, Klainer SM. Fiber-optic fluorescence carbon dioxide sensor for environmental monitoring. Microchim Acta 1998; 129: 181-8.

[40] Portaccio M, Lepore M, Della Ventura B, et al. Fiber-optic glucose biosensor based on glucose oxidase immobilised in a silica gel matrix. J Sol-Gel Sci Technol 2009; 50(3): 437-48.

[41] McDonagh C, Burke CS, MacCraith BD. Optical chemical sensors. Chem Rev 2008; 108(2): 400-22.

[42] Wolfbeis OS. Materials for fluorescence-based optical chemical sensors. J Mater Chem 2005; 15(27-28): 2657-69. 
[43] Thompson RB, Lakowicz JR. Fiber optic pH sensor based on phase fluorescence lifetimes. Anal Chem 1993; 65(7): 853-6.

[44] Epstein JR, Walt DR. Fluorescence-based fibre optic arrays: A universal platform for sensing. Chem Soc Rev 2003; 32(4): 203-14.

[45] Chu CS, Lo YL, Sung TW. Review on recent developments of fluorescent oxygen and carbon dioxide optical fiber sensors. Photon Sens 2011; 1(3): 234-50.

[46] Stern O, Volmer M. Über die Abklingzeit der Fluoreszenz. Physik Zeitschr 1919; 20: 183-8.

[47] Goicoechea J, Zamarreño CR, Matias IR, Arregui FJ. Minimizing the photobleaching of self-assembled multilayers for sensor applications. Sens Actuators B-Chem 2007; 126(1): 41-7.

[48] Garcia Moreda FJ, Arregui FJ, Achaerandio M, Matias IR. Study of indicators for the development of fluorescence based optical fiber temperature sensors. Sens Actuators B-Chem 2006; 118(1-2): 42532.

[49] MacCraith BD, McDonagh C. Enhanced fluorescence sensing using sol-gel materials. J Fluoresc 2002; 12(3-4): 333-42.

[50] Kasik I, Mrazek J, Martan T, Pospisilova M, Podrazky O, Matejec V, Hoyerova K, Kaminek M. Fiber-optic pH detection in small volumes of biosamples. Anal Bioanal Chem 2010; 398(5): 1883-9.

[51] Chu CS, Lo YL. Highly sensitive and linear optical fiber carbon dioxide sensor based on sol-gel matrix doped with silica particles and HPTS. Sens Actuators B-Chem 2009; 143(1): 205-10.

[52] Lo YL, Chu CS. Proceedings of SPIE 7004: 19th International Conference on Optical Fibre Sensors 2008; 2008.

[53] Jin W, Jiang J, Song Y, Bai C. Real-time monitoring of blood carbon dioxide tension by fluorosensor. Respir Physiol Neur 2012; 180(1): 141-6.

[54] Gonçalves HMR, Maule CD, Jorge PAS, Esteves da Silva JCG. Fiber optic lifetime $\mathrm{pH}$ sensing based on ruthenium(II) complexes with dicarboxybipyridine. Anal Chim Acta 2008; 626(1): 62-70.

[55] Grant PS, McShane MJ. Development of multilayer fluorescent thin film chemical sensors using electrostatic self-assembly. IEEE Sens J 2003; 3(2): 139-46.

[56] Wang JY, Chen BX, Chu FH. Experimental study of dissolved oxygen sensing based on plastic opt fiber. Guangdianzi Jiguang 2012; 23(1): 121-5.

[57] Chu F, Yang J, Cai H, Qu R, Fang Z. Characterization of a dissolved oxygen sensor made of plastic optical fiber coated with ruthenium-incorporated solgel. Appl Opt 2009; 48(2): 338-42.

[58] Wallave PA, Elliott N, Uttamlal M, Holmes-Smith AS, Campbell M. Development of a quasi-distributed optical fibre $\mathrm{pH}$ sensor using a covalently bound indicator. Meas Sci Technol 2001; 12(7): 882-6.

[59] Kasik I, Martan T, Podrazky O, Mrazek J, Pospisilova M, Matejec V. Proceedings of SPIE 7356: Opti Sens 2009; 2009.

[60] Martan T, Pospisilova M, Aubrecht J, Mrazek J, Podrazky O, Kasik I, Matejec V. Journal of Physics: Conference Series 206 (2010) 012017: 2009 Euro-American Workshop on Information Optics $2009 ; 2010$.

[61] Nguyen TH, Hardwick SA, Sun T, Grattan KTV. Intrinsic fluorescence-based optical fiber sensor for cocaine using a molecularly imprinted polymer as the recognition element. IEEE Sens J 2012; 12(1): 255-60.

[62] Yang XH, Wang LL. Fluorescence $\mathrm{pH}$ probe based on microstructured polymer optical fiber. Opt Express 2007; 15(25): 16478-83.

[63] Peng L, Yang X, Yuan L, et al. Gaseous ammonia fluorescence probe based on cellulose acetate modified microstructured optical fiber. Opt Commun 2011; 284(19): 4810-4.

[64] Ma J, Kos A, Bock WJ, et al. Proceedings of SPIE 7653: Fourth European Workshop on Optical Fibre Sensors 2010.

[65] Chiniforooshan Y, Ma J, Bock WJ, Hao W, Wang ZY. Proceedings of SPIE 8370: Fiber Optic Sensors and Applications IX; 2012.

[66] Richardson AC, Foo TC, Englich FV, Ebendorff-Heidepriem H, Sumby CJ, Monro TM. Proceedings of SPIE 8351: 3rd Asia Pacific Optical Sensors Conference 2012.

[67] Zamarreño CR, Bravo J, Goicoechea J, Matias IR, Arregui FJ. Response time enhancement of $\mathrm{pH}$ sensing films by means of hydrophilic nanostructured coatings. Sens Actuators B-Chem 2007; 128(1): 138-44.

[68] Gonçalves HMR, Duarte AJ, Esteves da Silva JCG. Optical fiber sensor for $\mathrm{Hg}(\mathrm{II})$ based on carbon dots. Biosens Bioelectron 2010; 26(4): 1302-6.

[69] Gonçalves HMR, Duarte AJ, Davis F, Higson SPJ, Esteves da Silva JCG. Layer-by-layer immobilization of carbon dots fluorescent nanomaterials on single optical fiber. Anal Chim Acta 2012; 735 : 90-5.

[70] Weidemaier K, Lastovich A, Keith S, Pitner JB, Sistare M, Jacobson R, Kurisko D. Multi-day pre-clinical demonstration of glucose/galactose binding protein-based fiber optic sensor. Biosens Bioelectron 2011; 26(10): 4117-23.

[71] Jorge P, Martins MA, Trindade T, Santos JL, Farahi F. Optical fiber sensing using quantum dots. Sensors 2007; 7(12): 3489-534.

[72] De Bastida G, Arregui FJ, Goicoechea J, Matias IR. Quantum dotsbased optical fiber temperature sensors fabricated by layer-bylayer. IEEE Sens J 2006; 6(6): 1378-79.

[73] Bravo J, Goicoechea J, Corres JM, Arregui FJ, Matias IR. Encapsulated quantum dot nanofilms inside hollow core optical fibers for temperature measurement. IEEE Sens J 2008; 8(7): 1368-74.

[74] Larrion B, Hernaez M, Arregui FJ, Goicoechea J, Bravo J, Matias IR. Photonic crystal fiber temperature sensor based on quantum dot nanocoatings. J Sens 2009; 2009: 6.

[75] Sung TW, Lo YL. Highly sensitive and selective sensor based on silica-coated $\mathrm{CdSe} / \mathrm{ZnS}$ nanoparticles for $\mathrm{Cu} 2+$ ion detection. Sens Actuators B-Chem 2012; 165(1): 119-25.

[76] Ciaccheri L, Samano Baca EE, Russo MT, Ottevaere H, Thienpont H, Mignani AG. Proceedings of SPIE 8439: Opt Sens Detect II 2012.

[77] Mignani AG, Ciaccheri L, Gordillo B, et al. Identifying the production region of single-malt Scotch whiskies using optical spectroscopy and pattern recognition techniques. Sens Actuators B-Chem 2012; 171-172: 458-62.

[78] Mignani AG, Ciaccheri L, Ottevaere H, et al. Diffuse-light absorption spectroscopy in the VIS and NIR spectral ranges for adulteration assessment of extra virgin olive oils. Lect Notes Electr Eng 2011; 91: 431-7.

[79] Bunganaen Y, Lamb DW. An optical fibre technique for measuring optical absorption by chromophores in the presence of scattering particles. J Phys Conf Ser 2005; 15(1): 67-73.

[80] Mathew J, Semenova Y, Farrell G. A fiber bend based humidity sensor with a wide linear range and fast measurement speed. Sens Actuators A-Phys 2012; 174(1): 47-51.

[81] Zhao Z, Duan Y. A low cost fiber-optic humidity sensor based on silica sol-gel film. Sens Actuators B-Chem 2011; 160(1): 1340-5.

[82] Surre F, Lyons B, Sun T, et al. U-bend fibre optic $\mathrm{pH}$ sensors using layer-by-layer electrostatic self-assembly technique. J Phys Conf Ser 2009; $178: 012046$.

[83] Tao S, Xu L, Fanguy JC. Optical fiber ammonia sensing probes using reagent immobilized porous silica coating as transducers. Sens Actuators B-Chem 2006; 115(1): 158-63.

[84] $\mathrm{Hu} X$, Tao $\mathrm{S}$. An optical fiber $\mathrm{H}_{2} \mathrm{O}_{2}$-sensing probe using a titanium(IV) oxyacetylacetonate immobilized nafion coating on an bent optical fiber probe. IEEE Sens J 2011; 11(9): 2032-6.

[85] Kalvoda L, Aubrecht J, Klepacek R, Lukasova P. Proceedings of SPIE 7653: 4th European Workshop on Optical Fibre Sensors 2010.

[86] Kodaira S, Korposh S, Lee SW, Batty WJ, James SW, Tatam RP. 3rd International Conference on Sensing Technology, ICST 2008; 2008.

[87] Korposh S, Kodaira S, Batty W, James SW, Lee SW. Nanoassembled thin-film gas sensor II. An intrinsic highly sensitive fibre optic sensor for ammonia detection. Sens Mater 2009; 21(4): 179-89.

[88] Urrutia A, Rivero PJ, Goicoechea J, Arregui FJ, Matias IR. 5th International Conference on Sensing Technology, ICST 2011; 2011.

[89] Arregui FJ, Ciaurriz Z, Oneca M, Matias IR. An experimental study about hydrogels for the fabrication of optical fiber humidity sensors. Sens Actuators B-Chem 2003; 96: 165-72.

[90] Zaharescu M, Barau A, Predoana L, et al. $\mathrm{TiO}_{2}-\mathrm{SiO}_{2}$ sol-gel hybrid films and their sensitivity to gaseous toluene. J Non Cryst Solids 2008; 354(2-9): 693-9.

[91] Angelini E, Grassini S, Mombello D, Neri A, Parvis M, Perrone G. Plasma modified POF sensors for in situ environmental monitoring of museum indoor environments. Appl Phys A 2010; 100(3): 97580.

[92] Neri A, Parvis M, Perrone G, Grassini S, Angelini E, Mombello D. IEEE Sensors 2008; 2009.

[93] Kulkarni A, Lee J-, Nam J-, Kim T. Thin film-coated plastic optical fiber probe for aerosol chemical sensing applications. Sens Actuators B-Chem 2010; 150(1): 154-9. 
[94] Belhadj Miled O, Ben Ouada H, Livage J. pH sensor based on a detection sol-gel layer onto optical fiber. Mater Sci Eng CBiomimetic Supramol Syst 2002; 21(1-2): 183-8.

[95] Dong S, Luo M, Peng G, Cheng W. Broad range $\mathrm{pH}$ sensor based on sol-gel entrapped indicators on fibre optic. Sens Actuators BChem 2008; 129(1): 94-8.

[96] Gupta BD, Sharma DK. Evanescent wave absorption based fiber optic $\mathrm{pH}$ sensor prepared by dye doped sol-gel immobilization technique. Opt Commun 1997; 140(1-3): 32-5.

[97] Sharma NK, Gupta BD. Fabrication and characterization of a fiberoptic $\mathrm{pH}$ sensor for the $\mathrm{pH}$ range 2 to 13. Fiber Integr Opt 2004; 23(4): 327-35.

[98] Alvarado-Méndez E, Rojas-Laguna R, Andrade-Lucio JA, Hernández-Cruz D, Lessard RA, Aviña-Cervantes JG. Design and characterization of $\mathrm{pH}$ sensor based on sol-gel silica layer on plastic optical fiber. Sens Actuators B-Chem 2005; 106(2): 518-22.

[99] Wu S, Cheng W, Qiu Y, Li Z, Shuang S, Dong C. Fiber optic pH sensor based on mode-filtered light detection. Sens Actuators BChem 2010; 144(1): 255-9.

[100] Rayss J, Sudolski G. Ion adsorption in the porous sol-gel silica layer in the fibre optic pH sensor. Sens Actuators B-Chem 2002; 87(3): 397-405.

[101] Rayss J, Sudolski G. Proceedings of SPIE 5124: Optoelectronic and Electronic Sensors V 2002.

[102] Gui Z, Qian J, Yin M, An Q, Gu B, Zhang A. A novel fast response fiber-optic $\mathrm{pH}$ sensor based on nanoporous self-assembled multilayer films. J Mater Chem 2010; 20(36): 7754-60.

[103] Goicoechea J, Zamarreño CR, Matías IR, Arregui FJ. Optical fiber $\mathrm{pH}$ sensors based on layer-by-layer electrostatic self-assembled Neutral Red. Sens Actuators B-Chem 2008; 132(1): 305-11.

[104] Zamarreño CR, Hernaez M, Matias IR, Arregui FJ. IEEE Sensors 2009.

[105] Luna-Moreno D, Monzon-Hernandez D, Calixto-Carrera S, Espinosa-Luna R. Tailored Pd-Au layer produced by conventional evaporation process for hydrogen sensing. Opt Lasers Eng 2011; 49(6): 693-7.

[106] Monzón-Hernández D, Luna-Moreno D, Martínez-Escobar D. Fast response fiber optic hydrogen sensor based on palladium and gold nano-layers. Sens Actuators B-Chem 2009; 136(2): 562-6.

[107] Akita S, Sasaki H, Watanabe K, Seki A. A humidity sensor based on a hetero-core optical fiber. Sens Actuators B-Chem 2010; 147(2): 385-91.

[108] Matias IR, Arregui FJ, Corres JM, Bravo J. Evanescent field fiberoptic sensors for humidity monitoring based on nanocoatings. IEEE Sens J 2007; 7(1): 89-95.

[109] Morisawa M, Muto S. Plastic optical fiber sensing of alcohol concentration in liquors. J Sensors 2012: 709849

[110] Gupta BD, Sharma S. A long-range fiber optic $\mathrm{pH}$ sensor prepared by dye doped sol-gel immobilization technique. Opt Commun 1998; 154(5-6): 282-4.

[111] Yang M, Liu H, Zhang D, Tong X. Hydrogen sensing performance comparison of $\mathrm{Pd}$ layer and $\mathrm{Pd} / \mathrm{WO}_{3}$ composite thin film coated on side-polished single- and multimode fibers. Sens Actuators BChem 2010; 149(1): 161-4.

[112] Seki A, Katakura H, Kai T, Iga M, Watanabe K. A hetero-core structured fiber optic pH sensor. Anal Chim Acta 2007; 582(1): 154-7.

[113] Minkovich VP, Monzón-Hernández D, Villatoro J, Badenes G. Microstructured optical fiber coated with thin films for gas and chemical sensing. Opt Express 2006; 14(18): 8413-8.

[114] Huyang G, Canning J, Aslund ML, Naqshbandi M, Stocks D, Crossley MJ. Proceedings of SPIE 7653: 4th European Workshop on Optical Fibre Sensors; 2010.

[115] Alvarado-Méndez E, Flores-Rangel SD, Hernández-Cruz D, et al. Proc. SPIE 7839: 2nd Workshop on Specialty Optical Fibers and Their Applications; 2010.

[116] Wu Q, Semenova Y, Mathew J, Wang P, Farrell G. Humidity sensor based on a single-mode hetero-core fiber structure. Opt Lett 2011; 36(10): 1752-4.

[117] Yang F, Sambles JR. Determination of the optical permittivity and thickness of absorbing films using long range modes. J Mod Opt 1997; 44(6): 1155-63.

[118] Jorgenson RC, Yee SS. A fiber-optic chemical sensor based on surface plasmon resonance. Sens Actuators B-Chem 1993; 12(3): 213-20.
[119] Chiu M, Shih C. Searching for optimal sensitivity of single-mode D-type optical fiber sensor in the phase measurement. Sens Actuators B-Chem 2008; 131(2): 596-601.

[120] Homola J. On the sensitivity of surface plasmon resonance sensors with spectral interrogation. Sens Actuators B-Chem 1997; 41(1-3): 207-11.

[121] Piliarik M, Homola J, Manikova Z, Ctyroky J. Surface plasmon resonance sensor based on a single-mode polarization-maintaining optical fiber. Sens Actuators B-Chem 2003; 90(1-3): 236-42.

[122] Slavik R, Homola J, Ctyroky J. Single-mode optical fiber surface plasmon resonance sensor. Sens Actuators B-Chem 1999; 54(1-2): 74-9.

[123] Chen C, Tsao T, Li W, et al. Novel U-shape gold nanoparticlesmodified optical fiber for localized plasmon resonance chemical sensing. Microsyst Technol 2010; 16(7): 1207-14.

[124] Lin WB, Lacroix M, Chovelon JM, Jaffrezic-Renault N, Gagnaire H. Development of a fiber-optic sensor based on surface plasmon resonance on silver film for monitoring aqueous media. Sens Actuators B-Chem 2001; 75(3): 203-9.

[125] Navarrete MC, Diaz-Herrera N, Gonzalez-Cano A, Esteban O. A polarization-independent SPR fiber sensor. Plasmonics 2010; 5(1): 7-12.

[126] Singh S, Gupta BD. Fabrication and characterization of a highly sensitive surface plasmon resonance based fiber optic $\mathrm{pH}$ sensor utilizing high index layer and smart hydrogel. Sens Actuators BChem 2012; 173: 268-73.

[127] Allsop T, Neal R, Davies EM, et al. Low refractive index gas sensing using a surface plasmon resonance fibre device. Meas Sci Technol 2010; 21: 094029.

[128] Allsop T, Neal R, Mou C, et al. Formation and characterization of ultra-sensitive surface plasmon resonance sensor based upon a nano-scale corrugated multi-layered coated D-shaped optical fiber. IEEE J Quantum Electron 2012; 48(3): 394-405.

[129] Mishra SK, Kumari D, Gupta BD. Surface plasmon resonance based fiber optic ammonia gas sensor using ITO and polyaniline. Sens Actuators B-Chem 2012; 171-172: 976-83.

[130] Homola J. Present and future of surface plasmon resonance biosensors. Anal Bioanal Chem 2003; 377(3): 528-39.

[131] Marazuela MD, Moreno-Bondi MC. Fiber-optic biosensors - An overview. Anal Bioanal Chem 2002; 372(5-6): 664-82.

[132] Chang YF, Chen RC, Lee YJ, Chao SC, Su LC, Li YC, Chou C. Localized surface plasmon coupled fluorescence fiber-optic biosensor for alpha-fetoprotein detection in human serum. Biosens Bioelectron 2009; 24(6): 1610-4

[133] Chang YF, Wang SF, Huang JC, Su LC, Yao L, Li YC, Wu SC, Chen YM, Hsieh JP, Chou C. Detection of swine-origin influenza A (H1N1) viruses using a localized surface plasmon coupled fluorescence fiber-optic biosensor. Biosens Bioelectron 2010; 26(3): 1068-73.

[134] Huang JC, Chang YF, Chen KH, et al. Detection of severe acute respiratory syndrome (SARS) coronavirus nucleocapsid protein in human serum using a localized surface plasmon coupled fluorescence fiber-optic biosensor. Biosens Bioelectron 2009; 25(2): 3205.

[135] Rajan, Chand S, Gupta BD. Surface plasmon resonance based fiber-optic sensor for the detection of pesticide. Sens Actuators BChem 2007; 123(2): 661-6.

[136] Yanase Y, Araki A, Suzuki H, et al. Development of an optical fiber SPR sensor for living cell activation. Biosens Bioelectron 2010; 25(5): 1244-7.

[137] Del Villar I, Zamarreño CR, Hernaez M, Arregui FJ, Matias IR. Generation of lossy mode resonances with absorbing thin-films. J Lightwave Technol 2010; 28(23): 3351-7.

[138] Zamarreño CR, Hernaez M, Del Villar I, Matias IR, Arregui FJ. ITO coated optical fiber refractometers based on resonances in the infrared region. IEEE Sens J 2010; 10(2): 365-6.

[139] Zamarreño CR, Sanchez P, Hernaez M, Villar ID, FernandezValdivielso C, Matias IR, Arregui FJ. Dual-peak resonance-based optical fiber refractometers. IEEE Photon Technol Lett 2010; 22(24): 1778-80.

[140] Hernaez M, Zamarreño CR, Fernandez-Valdivielso C, Del Villar I, Arregui FJ, Matias IR. Agarose optical fibre humidity sensor based on electromagnetic resonance in the infra-red region. Phys Status Solidi C Curr Top Solid State Phys 2010; 7(11-12): 2767-9.

[141] Socorro AB, Villar ID, Corres JM, Arregui FJ, Matias IR. Tapered single-mode optical fiber $\mathrm{pH}$ sensor based on lossy mode reso- 
nances generated by a polymeric thin-film. IEEE Sens J 2012; 12(8): 2598-603.

[142] Hernaez M, Villar ID, Zamarreño CR, Arregui FJ, Matias IR. Optical fiber refractometers based on lossy mode resonances supported by $\mathrm{TiO}_{2}$ coatings. Appl Opt 2010; 49(20): 3980-5.

[143] Zamarreño CR, Hernaez M, Del Villar I, Matias IR, Arregui FJ. Optical fiber $\mathrm{pH}$ sensor based on lossy-mode resonances by means of thin polymeric coatings. Sens Actuators B-Chem 2011; 155(1): 290-7.

[144] Allsop T, Neal R, Mou C, et al. Multilayered coated infra-red surface plasmon resonance fibre sensors for aqueous chemical sensing. Opt Fiber Technol 2009; 15(5-6): 477-82.

[145] Pollet J, Delport F, Janssen KP, et al. Fiber optic SPR biosensing of DNA hybridization and DNA-protein interactions. Biosens Bioelectron 2009; 25(4): 864-69.

[146] Lin TJ, Chung MF. Detection of cadmium by a fiber-optic biosensor based on localized surface plasmon resonance. Biosens Bioelectron 2009; 24(5): 1213-8.
[147] Allsop T, Nagel D, Neal R, et al. Proceedings of SPIE 7715: Biophotonics: Photonic Solutions for Better Health Care II 2010.

[148] Zamarreño CR, Hernaez M, Del Villar I, Matias IR, Arregui FJ. Proceedings Eurosensors XXIV 2010.

[149] Li C, Thostenson ET, Chou TW. Sensors and actuators based on carbon nanotubes and their composites: A review. Compos Sci Technol 2008; 68(6): 1227-49.

[150] Zhang H, Kulkarni A, Kim H, et al. Detection of acetone vapor using graphene on polymer optical fiber. J Nanosci Nanotechnol 2011; 11(7): 5939-43.

[151] Varghese SH, Nair R, Nair BG, et al. Sensors based on carbon nanotubes and their applications: A review. Curr Nanosci 2010; 6(4): 331-46.

[152] Rowsell JLC, Yaghi OM. Metal-organic frameworks: A new class of porous materials. Microporous Mesoporous Mater 2004; 73(12): 3-14.

Received: February 01, 2013

Revised: February 01, 2013

Accepted: December 10, 2013

(C) Hernáez et al.; Licensee Bentham Open.

This is an open access article licensed under the terms of the Creative Commons Attribution Non-Commercial License (http://creativecommons.org/licenses/by-nc/3.0/) which permits unrestricted, non-commercial use, distribution and reproduction in any medium, provided the work is properly cited. 